\title{
ADVANTAGES OF RETAIL STRATEGIES FOR ASSORTMENT LINE DIFFERENTIATION
}

\author{
S. Petrova* \\ Department of Commerce, Faculty of Industry and Commerce, D. A. Tsenov Academy \\ of Economics, Svishtov, Bulgaria
}

\begin{abstract}
Modern retailers differentiate the offered assortment composition horizontally or vertically in order to meet the different, specific and heterogeneous customer requirements. The main purpose of this paper is to interpret basic theoretical and methodological assumptions regarding the nature of strategies for assortment line differentiation and, on this basis, to provide successful retail practice examples taking into account the preferences of the target customer segments. The research issues thus outlined require that a study into the specialized literature be carried out. Conceptual ideas and opinions on the process of assortment line differentiation are presented. The scientific methods of theoretical and empirical research that are used are: factor analysis and synthesis, comparison, generalization, induction and deduction, figures and tables for data visualization. The outcomes of the study are synthesized in the conclusions formulated and are linked to outlining the benefits of an appropriately chosen strategy for assortment line differentiation for retailers.
\end{abstract}

Key words: Retailers; Retail assortment; Retailers' assortment decisions.

\section{INTRODUCTION}

In today's highly competitive business environment retailers are faced with searching for strategic tools for development, among which the decisions for assortment line differentiation stand out. Retailers differentiate the offered assortment composition horizontally or vertically to meet the different, specific and heterogeneous requirements of customers.

The main purpose of this paper is to interpret basic theoretical and methodological assumptions regarding the nature of strategies for assortment line differentiation and, on this basis, to provide successful retail practice examples taking into account the preferences of the target customer segments.

In order to achieve the research aim, the following tasks are identified: defining basic theoretical assumptions regarding the nature of

Correspondence to: S. Petrova, Faculty of Industry and Commerce, D. A. Tsenov Academy of Economics, Svishtov, Bulgaria, 2, Emanuil Chakarov Street, 5250, e-mail: s.petrova@unisvishtov.bg, mobile phone: +359886580689 differentiation; clarifying some methodological aspects of the strategies for assortment line differentiation formed by retailers; testing the conceptual ideas for assortment line differentiation on the basis of a targeted study of the retail practice; drawing out conclusions and outlining benefits of implementing chosen strategies for assortment line differentiation for retailers.

The research problems thus outlined require that a study into the specialized literature be carried out. Conceptual ideas, views and opinions regarding assortment composition differentiation are presented. Emphasis is placed on the understanding that the implementation of differentiation strategies of the offered assortment lines is relevant and practically applicable for any retail company that aims to achieve the desired level of sales and profits under the conditions of a dynamic and competitive market. Two large retail chains operating on the Bulgarian market Billa Bulgaria EOOD and Kaufland Bulgaria $\mathrm{KD}$ - are identified as the object of study in the paper. The strategies applied by the two retail companies for assortment line differentiation on the example of groceries, in particular the 
promising product category 'Chocolate and chocolate goods', are subject to analysis and evaluation.

The following important scientific methods of theoretical and empirical research are used in the paper: analysis and synthesis, comparison and generalization, induction and deduction, figures and tables for data visualization. For the purposes of the study, the data is processed using the SPSS software product.

\section{THEORETICAL FRAMEWORK OF THE STRATEGIES FOR ASSORTMENT LINE DIFFERENTIATION}

A number of researchers, including $M$. Draganska and D. Jain, analyzing changes in the retail industry over the past decades, have come up with statements and maxims to significantly expand the range of assortment compositions offered by retailers (1). According to the above cited authors, in the period 1990-2004 in retail formats such as supermarkets, for example, the average number of stock-keeping units (SKUs) included in the assortment increased from 16,500 to 25,153 . These values allow for reporting an increase rate of $52.44 \%$, which can be defined as a high value for the measured relative quantity of dynamics.

A basic element of the interpreted trend is the increase in the assortment line depth, the definition of which in the fundamental assumptions is reduced to the number of articles belonging to that line. Complying with the definitions given in the specialized literature allows for characterizing assortment line depth via the number of variants within the existing product categories. This definition does not contradict the previous one.

Retailers should take into account the impact of the market factors that force them to expand their assortment lines through an increase or saturation. Of particular importance is the extent to which article-specific attributes included within an assortment line determine which lines have to be deep and which ones have to remain shallow. At the same time, the impact of the degree of points of sale differentiation on strategic decisions regarding assortment depth is subject to evaluation.

There are a number of studies in the specialized literature on the nature of incentives that underlie the decisions regarding assortment line differentiation (2). In their analyses and evaluations researchers $P$.
Messinger and $C$. Narasimhan highlight permissible and probable reasons to stock more articles in stores, such as seeking economies of scale in business activities, technological improvement, higher margins, lower inventory cost. Besides, each of these factors is evaluated in favour of the theory based on consumers' desire to minimize shopping time. In addition, retailers are expanding their retail assortment by forming a deeper equilibrium assortment in certain product categories and, shallower in others.

In specialized theory, a large group of researchers working in this field have conducted fundamentally significant studies in which they seek to identify the relationship between assortment line differentiation and the sales volume in a given assortment line. Theoreticians, such as G. Van Ryzin and S. Mahajan, outline an increasing positive relationship between assortment differentiation and article sales (3). Problem areas, as highlighted by $P$. Boatwright and J. Nunes, are associated with clarifying the negative relationship between the two evaluated variables (4).

The analyses of the above cited researchers contribute to distinguishing the circumstances in which assortment line differentiation is linked to realize sales. It is stated that the relationship between assortment depth and sales is critically dependent on the degree of differentiation between the variants in the assortment line. In this sense, it is assumed that, on the one hand, there is a positive relationship between the assortment depth and sales in more differentiated assortment lines and, on the other hand, a negative relationship between the assortment depth and sales in less differentiated assortment lines.

It is argued that the equilibrium assortment depth follows an inverted U-shape as regards assortment differentiation. The change in the differentiation is estimated as a significant prerequisite for achieving equilibrium depth of assortment lines, with retailers choosing a depth that meets customer requirements and attracts new customers.

Better expressed customer loyalty is thought to lead to higher prices, reducing the ability of retailers to use selective price discounts to attract new customers to their stores. Providing a deeper assortment of articles enhances sales volume and retailers' profits and also serves as a strategic tool for increasing market share. 
Therefore, increasing the number of customers served by a single retailer becomes a prerequisite for offering a deeper assortment, while increasing loyalty leads to the formation of shallower retail assortments. The interdependencies between the assortment depth, product differentiation and stores need to be highlighted.

Authors such as K. Nolega, M. Oloko, S. William and E. Oteki, confirm that in the specialized literature the concept of product differentiation, first proposed by $E$. Chamberlin in 1933 in the Theory of Monopolistic Competition, is defined by marketers as one of the most commonly used competitive strategies (5).

Interpreting the existing types of differentiation strategies at different levels goods, stores, assortments, assortment lines, assortment depth, etc., makes it possible to give examples of their successful implementation in retail practice.

In line with the research aim set in this paper, the proper implementation of the strategy for assortment line differentiation can provide retailers with the desired level of sales and profits, even when operating in a highly competitive market. A closer examination of the principle of strategy implementation requires a broader characterization of market conditions. As a rule, highly competitive markets are characterized by a greater number of players, the presence of leaders and the constant emergence of new companies. It is assumed that retailers make decisions about whether to offer homogeneous goods with similar and approximate characteristics on the market, or to have opportunities for wider differentiation and meeting the more different and heterogeneous customer requirements.

Retail practice shows that in highly competitive markets, small-sized companies can also exist by offering differentiated assortment lines to specific customer segments. Assortment line differentiation reduces the level of direct competition, makes it difficult to compare assortment items with each other, and enables retailers to become competitive in the market. The higher the degree of differentiation of the assortment lines is, the wider the consumer choice and the more difficult the comparison of assortments.

The specialized theory distinguishes two types of differentiation of goods - horizontal and vertical. As A. Spence states, horizontal differentiation is associated with the supply of different goods for different needs, and vertical differentiation - different goods for one need (6). The two different types of differentiation complement each other and can coexist in the retailers' assortment portfolio. Therefore, retailers differentiate their assortment lines horizontally and vertically to meet similar as well as different and heterogeneous customer needs. Part of the assortment involves articles that differ not so much in quality but in individual attributes, such as aroma, colour, and packaging, related to horizontal differentiation. For example, in the product category of yoghurt, separate assortment lines can be offered, differing in quality and price range. Within each of the lines studied, assortment items having the same price can be grouped together. Retailers take into account the differences in consumer preferences and use them as a tool for forming and differentiating assortment lines. In addition, as $V$. Blazheva confirms, the requirements of a new category of consumers who prefer environmentally friendly food should be taken into account, which is a reflection of the current eating trends $(7,8)$. At the same time, according to $V$. Perkov, retailers' shelf spaces built on certain economic models in search of optimal values are of great importance (9). As S. Iliychovski, T. Filipova and P. Midova state, the power of influence of factor conditions related to the established contacts with intermediaries, the possibilities for sale and the choice of retail format should be taken into account (10-12).

In order to apply a specific differentiation strategy in the retail practice, it is necessary to observe certain conditions, including: defining the attributes of the articles perceived as the starting point for differentiation; analyzing the properties of competing articles; highlighting the significant attributes of the articles for each consumer segment in the market. The attributes thus distinguished can serve as possible criteria for assortment line differentiation. Fulfilling the conditions described above is a good reason for finding free market niches on the basis of using the most appropriate differentiation strategy.

In theory, there are some views on the use of the following differentiation strategies, which can be applied individually or combined: strategy for differentiating goods; strategy for differentiating the characteristics of goods; 
price differentiation strategy; differentiation strategy by means of ancillary services; differentiation strategy through commercial communications; differentiation strategy through design and packaging, etc.

According to L. Kelchner's view, adopting a different type of differentiation strategy at a certain level is the result of consumer evaluations of differences in the attributes of articles included in retailers' assortment lines or compositions (13). The successful implementation of the above strategies is determined by the existing differences in the characteristics of articles, accompanied by variations in price, heterogeneous functionality or product design, distinctive advertising and promotional activities, differences in the access to assortments in terms of time and place, and others that create uniqueness for consumers.

\section{EMPIRICAL STUDIES ON THE DIFFERENTIATION OF RETAILERS' ASSORTMENT LINES}

The empirical database of the study in this paper involves information from official retail chain sites, published data from annual activity reports, as well as data on major economic outcomes for the built corporate ownership. The study uses data regularly collected by the National Statistical Institute for food retailers based on their annual accounts and other reports. The above cited institute collects, processes and presents statistics on the companies studied, which are categorized and classified into sector G 'Trade; repair of motor vehicles and motorcycles' according to the Classification of Economic Activities. The study takes into account the product specialization of the retailers surveyed. The empirical data thus formed helps to achieve the research aim.

Two of the largest leading retail chains on the Bulgarian market - Billa Bulgaria EOOD and Kaufland Bulgaria KD - are identified as the object of study in this part of the study, which apply competitive strategies for assortment line differentiation included in the offered assortment composition (Table 1).

Billa is the first international supermarket chain owned by the Austrian company REWE International AG, which has been operating on the Bulgarian market since 2000.

At present, the retail company has 130 stores in 38 towns in Bulgaria. Billa Bulgaria EOOD adds an assortment of goods manufactured under its own brands - BILLA Brand, BILLA Premium and Clever, to the offered assortment, some of which are produced in Bulgaria.

According to sales managers, in order to satisfy consumers, the supermarket chain provides ongoing sales promotions and offers, such as: a super price for favourite items at an attractive promotional price every week; weekly promotion for over 130 items at a promotional price every week; BILLA Card Promotion for over 600 promotional items each month with BILLA Card; A Grand offer providing a $25 \%$ discount on a group of items every Friday and Saturday with a BILLA Card; $50 \%$ discount for loyal customers by collecting points for selected items (14).

The other retail chain studied is Kaufland, established in Germany. In 2006 Kaufland Bulgaria KD built its first store on the territory of our country, while fourteen years later more than 59 hypermarkets are operating located in 34 towns of the country. According to data of the retail chain, the average sales area of each store is approximately 3,500 square meters.

A broader examination of the options for applying the strategies for assortment line differentiation formed by the two competing retail companies and the identification of the link between the differentiation level and the sales volume and profit necessitates the use of business indicators (Table 1).

In accordance with the data in Table 1, during the analyzed period 2016-2018 the change in the sales revenues of Billa Bulgaria EOOD and Kaufland Bulgaria KD slowed down but remained at a relatively good level. According to the data in the Table 1 in the sub-period 2018-2017 compared to the previous subperiod - 2017-2016, the sales revenue growth rates of the compared competing retailers registered a favourable development, while the measured profit growth rates decreased. Therefore, in the coming years, the forecasts for sales revenue growth of both retailers should be more moderate and more limited.

According to the members of the board of Kaufland Bulgaria KD opportunities are consistently and invariably being sought for expanding the assortment portfolio, introducing branded goods and running an active advertising campaign (15). 
Table 1. Dynamics of sales revenue and profit of Billa Bulgaria EOOD and Kaufland Bulgaria KD retail chains during the period 2016-2018

\begin{tabular}{|c|c|c|}
\hline Indicators of the retail chain business activity & 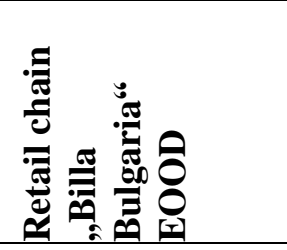 & 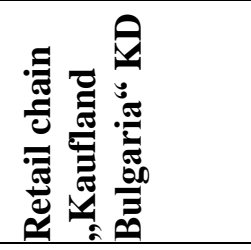 \\
\hline Columns & 1 & 2 \\
\hline Sales revenue in 2016 (thousand BGN) & 662756 & 1667418 \\
\hline Sales revenue in 2017 (thousand BGN) & 724070 & 1494983 \\
\hline Sales revenue in 2018 (thousand BGN) & 766454 & 1572523 \\
\hline Profit in 2016 (thousand BGN) & 5424 & 88045 \\
\hline Profit in 2017 (thousand BGN) & 4425 & 78158 \\
\hline Profit/loss in 2018 (thousand BGN) & -2247 & 71697 \\
\hline $\begin{array}{l}\text { Growth in sales revenue in } 2017 \text { compared to } \\
2016 \text { (in \%) }\end{array}$ & -18.42 & -10.34 \\
\hline $\begin{array}{l}\text { Growth in sales revenue in } 2018 \text { compared to } \\
2017 \text { (in \%) }\end{array}$ & 5.85 & 5.19 \\
\hline $\begin{array}{l}\text { Profit growth rate in } 2017 \text { compared to } 2016 \text { (in } \\
\% \text { ) }\end{array}$ & 9.25 & -11.23 \\
\hline $\begin{array}{l}\text { Profit growth rate in } 2018 \text { compared to } 2017 \text { (in } \\
\% \text { ) }\end{array}$ & -49.22 & -8.27 \\
\hline
\end{tabular}

Source: https://www.capital.bg/kpro/klasacii/k100/2019/08/05/3933339_verigite_za_potrebitelski_stoki_umeren i_kupuvachi/

In accordance with the subject of research in this part of the paper, related to the product category 'Chocolate and chocolate items' as well as on the basis of adopting a simulation model for exploring consumer preferences for items in certain assortment lines one can construct one-dimensional frequency distribution based on "What type of chocolate do you prefer? "The selected product category is determined by the specialists in retail practice as promising for development in Bulgaria (16).

For the research aim set, the data is processed using the SPSS software product (Table 2).

Table 2. Distribution of respondents by type of chocolate consumed

\begin{tabular}{|ll|l|l|l|l|}
\hline & & Frequency & Percent & $\begin{array}{l}\text { Valid } \\
\text { Percent }\end{array}$ & $\begin{array}{l}\text { Cumu- } \\
\text { lative } \\
\text { Percent }\end{array}$ \\
\hline Valid & white & 4 & 5.6 & 5.6 & 5.6 \\
& dark & 7 & 8.5 & 8.5 & 14.1 \\
& milk & 58 & 81.7 & 81.7 & 95.8 \\
Total & black & 3 & 4.2 & 4.2 & 100.0 \\
\hline
\end{tabular}

Analyzing the data illustrated by Table 2, we found that the highest relative share of the surveyed consumer group $-81.7 \%$, expressed a preference for milk chocolate, $8.5 \%$ of the respondents consumed dark chocolate. The lowest percentage of $4.2 \%$ measures the attractiveness of black chocolate. The assumption is that the attractiveness of the different types of chocolate is relative to their importance in making a purchase decision.
A more detailed description of the results of consumer perceptions of the characteristics of the analyzed articles from the studied assortment lines enables us to summarize that the two retail companies - Billa Bulgaria EOOD and Kaufland Bulgaria KD, in order to provide alternativity of consumer choices adopt horizontal and vertical differentiation strategies to varying degrees of application. The results of the evaluation of consumer preference at assortment line level contribute to the assumption that it is less dependent on 
the number of the assortment lines offered, which is along the horizontal line of the assortment composition, and is more dependent on the different articles, as being more closely interchangeable. The latter finding is consistent with the decisions of the retailers surveyed for the vertical differentiation of the assortment lines studied.

\section{CONCLUSIONS AND RECOMMENDATIONS}

The study thus conducted allows us to make the following important conclusions:

First, in a dynamic and highly competitive market environment, modern retailers use strategies for horizontal and vertical assortment line differentiation to focus on satisfying both the similar and the more diverse heterogeneous preferences of the different consumer segments.

Second, through horizontal differentiation, retail companies determine the difference in the assortment lines formed, whereas through vertical differentiation they seek to develop the assortment lines by increasing and saturating with a certain number of items. Retailers' decisions aim to diversify both the assortment lines and the items within each line.

Third, the analyses and evaluations carried out on the basis of using an appropriate set of empirical data regarding the possibilities for applying the types of strategies for assortment line differentiation formed by competing retail companies make it possible to highlight the fact that consumer preferences are less dependent on the number of horizontal assortment lines offered related to the horizontal differentiation and are more strongly dependent on the difference in the articles, which determines their interchangeability.

In its entirety, the proper use of strategies for assortment composition differentiation of retail companies can become a significant prerequisite for securing the sought level of sales and profits in a highly competitive market. Horizontal and vertical differentiation can complement each other and coexist in the retailers' assortment portfolio to meet the similar as well as the different and heterogeneous customer needs.

\section{REFERENCES}

1. Draganska, M., \& Jain, D. Product line length as a competitive tool. Econom. Management Strategy, 14(1), pp. 1-28, 2005.

2. Messinger, P., \& Narasimhan, C. A model of retail formats based on consumers' economizing on shopping time. Marketing Sci., 16(1), pp. 1-23, 1997.

3. Van Ryzin, G., \& Mahajan, S. On the relationship between inventory costs and variety benefits in retail assortments. Management Sci., 45(11), pp. 1496-1509, 1999.

4. Boatwright, P., \& Nunes, C. Reducing assortment: An attribute-based approach. Marketing, 65(1), pp. 50-63, 2001.

5. Nolega, K., Oloko, M., William, S., \& Oteki, E. Effects of Product Differentiation Strategies on Firm Product Performance: A Case of Kenya. International Journal of Novel Research in Marketing Management and Economics, 2, pp. 100-110, 2015.

6. Spence, A. Product differentiation and welfare. American Economic Review, 66(3), pp. 407-414, 1976.

7. Blazheva, V. Challenges facing the EU Common Agricultural Policy, Proceedings of the International Jubilee Scientific Conference "Economy and Management in the XXI century - solutions for stability and growth", Volume 4, Svishtov, pp. 284-288, 2011.

8. Blazheva, V. Regional and global manifestations of trading with agricultural produce, Proceedings of Roundtable with international participation "Commerce and tourism under conditions of smart, sustainable and inclusive growth", Volume II, Svishtov, pp. 203-207, 2016.

9. Perkov, V. Trade Modelling (application of mathematical methods and models in trade activities), V. Aprilov University Publishing House, Gabrovo, pp. 118-134, 2018.

10. Iliychovski, S. Commercial lending (economic and managerial aspects). Tsenov Academic Publishing House, Svishtov, pp. 62-75, 2008.

11. Filipova, T. Commercial brokerage in transactions with receivables (economic and managerial aspects, fragmentary approbation). Tsenov Academic Publishing house, Svishtov, pp. 8-25, 2009. 
12. Midova, P. Management of retail outlets. Tsenov Academic Publishing House, Svishtov, pp. 9-18, 2007.

13. Kelchner, L. (February 2019 r.). The Advantages of a Product Differentiation Strategy. Изтеглено на 28.03.2020 r. от https://smallbusiness.chron.com/advantages -product-differentiation-strategy17691.html

14. Who we are. (n.d.). Retrieved on 2803 2020 from https://www.billa.bg/zabilla/billa-koi-sme-nie
15. Gencheva, B. (05 082019 r.). Consumer goods chains: Moderate buyers. Retrieved on 28.03.2020 from https://www.capital.bg/kpro/klasacii/k100/2 019/08/05/3933339_verigite_za_potrebitels ki_stoki_umereni_kupuvachi/

16. Petrova, I. (03.12.2019 r.). The chocolate category in Bulgaria has a prospect for development. Retrieved on 28.03.2020 from

https://www.capital.bg/biznes/stoki_i_prod ajbi/2019/12/03/3986985_kategoriiata_na_s hokolada_v_bulgariia_ima_perspektiva 